\title{
Rennet-induced aggregation of homogenized milk: Impact of the presence of fat globules on the structure of casein gels
}

\author{
Gisèle Ion Titapiccolo, Marcela Alexander, Milena Corredig* \\ Department of Food Science, University of Guelph, Guelph, Ontario, N1G 2W1, Canada
}

Received 21 September 2009 - Revised 18 February 2010 - Accepted 1st March 2010

Published online 18 June 2010

\begin{abstract}
The present study investigated the renneting behaviour of casein micelles as influenced by the presence of fat globules. The gelation of skim milk, homogenized milk and homogenized milk with Tween 20 added was observed using diffusing wave spectroscopy and rheology. By adding Tween 20 to homogenized milk, it was possible to displace most of the milk protein from the oil/water interface and create a system with the same colloidal attributes as homogenized milk but with oil droplets with a very different interfacial composition, and relatively inert during rennetinduced aggregation. The primary phase of gelation was faster in homogenized milk compared to skim milk. Casein micelles were altered by the homogenization process which spreads them at the interface, making $\kappa$-casein more readily available. The addition of Tween 20 did not further affect the enzymatic activity on the micelles. However, the onset of gelation occurred earlier in homogenized milk with Tween 20 added, as the micelles aggregated at a lower level of proteolysis compared to homogenized milk. This work clearly showed that the gels formed in homogenized milk with and without Tween 20 have different physico-chemical properties, because of the different colloidal state of the filler particles.
\end{abstract}

homogenized milk / polysorbate / rennet coagulation / diffusing wave spectroscopy

\begin{abstract}
摘要 - 均质奶的酶凝乳: 脂肪球对酪蛋白胶束结构的影响。本文考察了脂肪球的存在对酪 蛋白胶束凝乳特性的影响。通过运用散射波谱和流变仪观察了脱脂奶、均质奶和添加吐 温 20 的均质奶的凝乳过程。吐温 20 添加到均质奶后, 可能会替代水包油界面中的大 多数乳蛋白, 形成了与均质奶具有相同胶体特性的新体系, 但是油滴界面成分会因此发 生变化，并且皱胃酶凝乳过程会相对缓慢。均质奶中凝胶相的形成比脱脂奶中要快。均 质过程使酪蛋白胶束向胶体界面扩散，从而 $\kappa$-酪蛋白更易获得。虽然添加吐温 20 不能进 一步影响胶束中酶活性, 但是, 添加吐温 20 的均质奶凝胶的形成比未添加吐温 20 的 要快, 这是由于添加吐温 20 的均质奶可以在较低的水解蛋白浓度下使酪蛋白胶体聚 合所致。该研究清楚的表明了由于填料颗粒具有不同的胶体状态导致了均质奶和添加 吐温 20 的均质奶形成的凝胶具有不同的物化特性。
\end{abstract}

\section{均质奶 / 聚山梨醇酯 / 皱胃酶凝乳 / 散射波谱}

Résumé - Agrégation induite par la présure de lait homogénéisé : impact de la présence de globules gras dans la structure des gels de caséine. Cette étude porte sur l'influence de la présence des globules gras sur le comportement des micelles de caséine après ajout de présure.

*Corresponding author (通讯作者): mcorredi@uoguelph.ca 
La gélification de lait écrémé, de lait homogénéisé et de lait homogénéisé additionné de Tween 20 a été observée par diffusion dynamique de la lumière et par rhéologie. En ajoutant du Tween 20 au lait homogénéisé, il était possible de déplacer la plupart des protéines adsorbées à l'interface huile/ eau et de créer un système avec les mêmes éléments colloïdaux que le lait homogénéisé mais avec des gouttelettes lipidiques ayant une composition à l'interface très différente et relativement inertes durant l'agrégation induite par la présure. La phase primaire de la gélification était plus rapide dans le lait homogénéisé en comparaison au lait écrémé. Les micelles de caséines étaient altérées par l'homogénéisation qui les disperse à l'interface, rendant les caséines kappa plus disponibles. L'addition de Tween 20 ne provoquait pas de modification supplémentaire de l'activité enzymatique sur les micelles. Cependant, le démarrage de la gélification apparaissait plus précocement dans le lait homogénéisé avec Tween 20, puisque les micelles s'agrégeaient à un niveau plus faible de protéolyse que celui du lait homogénéisé. Ces travaux montrent que les gels formés dans du lait homogénéisé additionné ou non de Tween 20 ont des propriétés physico-chimiques différentes, en raison de l'état colloïdal différent des particules de remplissage.

lait homogénéisé / polysorbate / coagulation présure / spectroscopie en diffusion dynamique de la lumière

\section{INTRODUCTION}

Fat globules play an important role in the texture of many food products, imparting desirable mouthfeel and carrying flavours. Many dairy products are mixed gels in which proteins are a constituent part of the network. When fat globules are dispersed in gelling milk, the microstructure and fracture behaviour of the gels are altered, with important consequences to texture. The dynamics of the assembly depend on the components present in the system, as well as the environmental conditions $(\mathrm{pH}$, temperature and ionic strength). The rennetinduced gelation of homogenized milk, in particular with regard to the effect of fat globules on the retention of moisture in cheese curd [13], on free oil [20, 28] and on yield [20], has been widely studied. However, very little is known about the dynamics of the interactions between the milk fat globules and the protein matrix in rennet-induced gels.

Fresh whole milk contains fat globules distributed in a range of diameters from 0.1 to $10 \mu \mathrm{m}$ [19]. The majority of the globules has a diameter $<0.15 \mu \mathrm{m}$ but represents a small volume of the total fat, while few of the globules are very large $(>10 \mu \mathrm{m})$ and are responsible for containing the majority of the mass of the milk fat. Homogenization of whole milk reduces the size of the fat globules by breaking them with strong shearing forces. This has the effect of increasing the total surface area of the globules by 4-10 times [19], which, in turn, generates the adsorption of proteins onto the interface to decrease the interfacial energy of the newly created surfaces. Casein micelles adsorb preferentially over whey proteins $[1,26]$, and these casein-coated fat globules have the ability to participate in the rennet-coagulation process of milk.

Enzymatic coagulation by rennet is the basis of the cheese-making process and is generally considered to be composed of two stages $[17,30]$. During the first stage, the proteolytic enzyme chymosin cleaves $\kappa$-casein, which mostly resides on the surface of the casein micelles. Because $\kappa$-casein is the main contributor to the stability of the micelles, its breakdown affects micellar charge and steric stabilization $[5,11]$, and, when a sufficient amount is cleaved, unstable casein micelles begin to aggregate [32]. Aggregation is the second stage of the rennet-coagulation process and leads to curd formation.

Studies have focused on the effect of homogenized fat globules on the properties of rennet gels. Fat globules in homogenized 
milk have different rennet-coagulation behaviour than native globules, due to the differences in size and interfacial composition $[10,14,18,21]$. Homogenized globules participate in the filled gel as "active fillers", i.e. they contribute, together with casein micelles, to the development of the gel matrix; on the contrary, native fat globules participate as "weakly interactive" or "inert fillers", occupying the voids within the casein strands because their membrane is not able to interact with casein micelles during coagulation [29].

It has been previously demonstrated, using model systems containing oil droplets of known size and composition in recombined milk, that the rheological and structural properties of milk gels depend on the composition of the fat globule surface $[6,9,14]$ as well as the colloidal state of the droplets $[8,23]$. To distinguish between the behaviour of "active" fat globules and "relatively inert" fat globules, homogenized milk with polysorbates (Tween 20) was also studied. It is known that small molecule surfactants are able to displace proteins from the surface of fat globules in emulsions [15], and it has been previously reported that during acid coagulation of recombined milk, fat globules with Tween 20 adsorbed at the interface behave as passive, "inert" fillers [2]. By comparing homogenized milk with and without Tween 20 it is possible to study systems with similar colloids characteristics (size and flocculation state) during rennet-induced coagulation of homogenized milk. Although Tween 20 has been used before to stabilize model emulsion droplets in recombined milk [2, 6, 9], the use of Tween 20 to displace protein in homogenized milk has yet to be reported as a way to study the impact of fat globule during the formation of structure of rennet casein gels.

This study analyses the behaviour of homogenized fat globules in milk during rennet coagulation. In recent years diffusing wave spectroscopy (DWS) has been employed to observe sol-gel transitions in milk without the need for dilution $[7,8,25$, 27]. By better understanding the beginning stages of aggregation, we may be able to apply approaches such as selective homogenization to increase curd yields, improve body and texture of reduced-fat products and design novel dairy gels.

\section{MATERIALS AND METHODS}

\subsection{Materials}

Fresh whole milk was collected from the Elora Dairy Research (Elora, ON, Canada), and sodium azide was added at a concentration of $0.2 \mathrm{~g} \cdot \mathrm{L}^{-1}$ to act as a bacteriostatic agent as soon as it was received.

Milk was then passed through a onestage high pressure homogenizer (Emulsiflex C5, Avestin, Ottawa, ON, Canada) at a pressure of $34.5 \mathrm{MPa}$. The homogenization was carried out for three consecutive passes. All the experiments on homogenized milk were performed the same day of homogenization unless otherwise indicated.

For skimming, milk was centrifuged at $4000 \times g$ for $20 \mathrm{~min}$ at $4{ }^{\circ} \mathrm{C}$ using a Beckman J2-21 centrifuge with JA-10 rotor (Beckman Coulter, Mississauga, ON, Canada) with subsequent filtration through Whatman glass fibre filters (Fisher Scientific, Whitby, ON, Canada); the filtration was repeated four times. Skim milk samples were stored at $4{ }^{\circ} \mathrm{C}$ and analysed within a week of preparation.

Polyoxyethylene sorbitan monolaurate (Tween 20, $1227 \mathrm{~g} \cdot \mathrm{mol}^{-1}$, Sigma Chemical Co, St. Louis, USA) was added to homogenized milk at a concentration of $2 \mathrm{~g}$ in $100 \mathrm{~mL}$. The milk was stirred for $6 \mathrm{~h}$ at room temperature before further analysis.

Chymostar Single Strength rennet (Rhodia, Cranbury, USA) was used at a concentration of $0.018 \mathrm{IMCU} \cdot \mathrm{mL}^{-1}$, at a temperature of $30{ }^{\circ} \mathrm{C}$ for gelation experiments. 
The samples were stirred for $30 \mathrm{~s}$ after rennet addition and immediately analysed by DWS or rheology.

\subsection{Transmission electron microscopy}

Transmission electron microscopy (TEM) was performed on homogenized milk prior to gelation. Initially, the fluid milk was prepared for thin sectioning by encapsulation in $20 \mathrm{~g} \cdot \mathrm{L}^{-1}$ agar tubes. Following primary fixation with a $20 \mathrm{~mL} \cdot \mathrm{L}^{-1}$ glutaraldehyde solution in Sorenson phosphate buffer $0.07 \mathrm{~mol} \cdot \mathrm{L}^{-1}$, $\mathrm{pH} 6.8$, the samples were post-fixed in $10 \mathrm{~mL} \cdot \mathrm{L}^{-1}$ osmium tetroxide solution in the same phosphate buffer. After dehydration in ethanol followed by propylene oxide using a gradient with higher alcohol concentration, samples were embedded in Spurr's low viscosity embedding media. The resin blocks were cut into sections 70-90 nm thick using a Reichert Ultracut E Ultramicrotome (Leica). The sections were stained with saturated uranyl acetate in water followed by Reynolds lead citrate solution. The sections were mounted on grids and examined with a TEM (Philips CM 10, Eindhoven, Holland) with an accelerating voltage of $60 \mathrm{kV}$. Typical magnification factors of 25000 46000 were used.

\subsection{Gel electrophoresis}

Sodium dodecyl sulphate polyacrylamide gel electrophoresis (SDS-PAGE) was performed using a Bio-Rad electrophoresis unit (Bio-Rad Laboratories Inc., Hercules, CA) to analyse the protein composition of the cream and serum phases in the homogenized milk samples. The cream was separated from the serum by centrifugation at $5000 \times g$ for $20 \mathrm{~min}$, using an Eppendorf 5415D centrifuge (Brinkmann Instruments Ltd., Mississauga, ON, Canada), dried on a filter paper for $30 \mathrm{~min}$ and resuspended in Milli-Q water maintaining the same fat concentration as in milk $\left(35 \mathrm{~g} \cdot \mathrm{L}^{-1}\right)$. Each sample was diluted $1: 2$ in reducing sample buffer (containing $1 \mathrm{~mol} \cdot \mathrm{L}^{-1}$ Tris $\mathrm{HCl}$, pH 6.8, $100 \mathrm{~g} \cdot \mathrm{L}^{-1} \mathrm{SDS}$, $750 \mathrm{~mL} \cdot \mathrm{L}^{-1}$ glycerol, $\beta$-mercaptoethanol, $10 \mathrm{~mL} \cdot \mathrm{L}^{-1}$ bromophenol blue) and heated for $5 \mathrm{~min}$ at $95{ }^{\circ} \mathrm{C}$. After heating, the samples were centrifuged (see above) before loading in the gel.

The resolving gel for the electrophoresis analysis contained $150 \mathrm{~mL} \cdot \mathrm{L}^{-1}$ acrylamide in $1.5 \mathrm{~mol} \cdot \mathrm{L}^{-1}$ Tris $\mathrm{HCl}$ at $\mathrm{pH} 8.9$, while the stacking gel was $40 \mathrm{~mL} \cdot \mathrm{L}^{-1}$ acrylamide in $0.1 \mathrm{~mol} \cdot \mathrm{L}^{-1}$ Tris $\mathrm{PO}_{4}$ buffer at $\mathrm{pH}$ 6.7. The electrophoresis buffer was $30 \mathrm{~g} \cdot \mathrm{L}^{-1}$ Tris $\mathrm{HCl}, 144 \mathrm{~g} \cdot \mathrm{L}^{-1}$ glycine and $10 \mathrm{~g} \cdot \mathrm{L}^{-1}$ $\mathrm{SDS}$ at $\mathrm{pH}$ 8.3. Aliquots of $7 \mu \mathrm{L}$ of the prepared samples were loaded into the gels and the electrophoresis separation was performed at $200 \mathrm{~V}$ for $40 \mathrm{~min}$. Gels were then stained with Coomassie blue in $500 \mathrm{~mL} \cdot \mathrm{L}^{-1}$ methanol and $100 \mathrm{~mL} \cdot \mathrm{L}^{-1}$ acetic acid for 30 min while shaking and destained with a solution of $450 \mathrm{~mL} \cdot \mathrm{L}^{-1}$ methanol and $100 \mathrm{~mL} \cdot \mathrm{L}^{-1}$ acetic acid for $1 \mathrm{~h}$. Samples were left overnight in a fresh destaining solution diluted 1:1 in Milli-Q water and scanned with a Sharp JX-330 scanner (Pharmacia Biotech).

\subsection{Light scattering}

The apparent average diameter of the different milk samples was measured using dynamic light scattering (DLS) (Zetasizer Nano, Malvern Instruments, Worcestershire, UK). The hydrodynamic size of the casein micelles was obtained from the average of three separate readings, on replicate samples. Samples were diluted $\sim 2000$ times in permeate (milk serum) and placed in the spectrometer right after dilution. Permeate was collected during the concentration of skim milk to a $2 x$ volume fraction by ultrafiltration (PLGC 10k regenerated cellulose cartridge, Millipore Corp., Bedford, MA), and it was filtered before use through a $0.22 \mu \mathrm{m}$ filter (Millipore Canada Ltd., 
Mississauga, ON, Canada). The dilution in permeate was performed to avoid multiple scattering while preserving the environmental conditions of the casein micelles.

The particle size distribution of the samples was also measured using integrated light scattering (Mastersizer 2000, Malvern Southborough, MA). The refractive indices used were 1.46 for milk fat and 1.33 for the dispersant (water). Each measurement was obtained from the average of three readings.

Samples were also analysed by DWS during renneting experiments. A volume of $\sim 1.5 \mathrm{~mL}$ of undiluted milk sample was placed into a flat-faced, $5 \mathrm{~mm}$ path length optical glass cuvette (Hellma Canada Ltd., Concord, Canada) and the temperature of the equipment was maintained at $30{ }^{\circ} \mathrm{C}$ with a water bath. The light source was a solid state diode pumped Nd:YAG laser (Coherent, Santa Clara, CA), of wavelength $532 \mathrm{~nm}$ and power of $100 \mathrm{~mW}$ and the transmitted scattered light was collected by a single fibre optic that was then bifurcated and fed to two matched photomultipliers (HC120-03, Hamamatsu, Loveland, $\mathrm{OH}$ ) and a correlator (FLEX2K-12 × 2, Bridgewater, NJ). Standard latex spheres of $260 \mathrm{~nm}$ diameter (Portland Duke Scientific, Palo Alto, CA) were used to calibrate the laser intensity daily. Correlation functions and intensity of the transmitted scattered light were measured at intervals of $2 \mathrm{~min}$ for $80 \mathrm{~min}$. Data were analysed using specialized software (DWS-Fit, Mediavention Inc., Guelph, ON, Canada). Each experiment was replicated at least three times, starting from different batches of fresh milk.

DWS is based on the measurement of temporal fluctuations of light that has been multiple-scattered by particles in a sample [16]. In recent years, it has been employed in the investigation of destabilization mechanisms in food systems [3, 27]. An exhaustive description of the equipment and theory can be found elsewhere [31]. Briefly, DWS relies on many scattering events happening as a photon of light traverses a colloidal dispersion and the light propagation is approximated by a random path distribution. DWS can yield information on the static properties (positional correlations) of a system via the photon transport mean free path, $l^{*}$, as well as dynamic properties via the decay time, $\tau$, and the mean square displacement (MSD). The value of $l^{*}$, function of the physical properties of the scatterers as well as their spatial correlation, can be determined experimentally by dividing the average intensity of the transmitted light of the sample, $T$, by that of a calibrating sample with well-determined $l^{*}$ [31]. The MSD is the average of the square of the distance travelled by the particles at a given time. In a free-diffusing regime, the motion is described as a random walk, for which the MSD increases linearly with time and the radii of the scatterers can be calculated via the Stokes-Einstein relation. In a gel, the particles will only be able to move a certain distance from their average position before being restricted in motion by their interactions with others. Therefore, at long times, their average displacement will reach a constant value [22].

\subsection{Rheology}

Rheological experiments were performed with a stress-controlled rheometer (AR 1000, TA Instrument Ltd., New Castle, USA), using a conical concentric cylinder geometry $(5920 \mu \mathrm{m}$ fixed gap, $15 \mathrm{~mm}$ radius and $42 \mathrm{~mm}$ cylinder immersed height). An external water bath (Isotemp 3016, Fisher Scientific, Whitby, Canada) was connected to the rheometer to keep the temperature of the sample at $30{ }^{\circ} \mathrm{C}$ for the duration of the experiment. After rennet addition, each sample was immediately placed in the rheometer and four successive tests were performed. First a time sweep was run at $0.5 \mathrm{~Pa}$ controlled stress, $1.0 \mathrm{~Hz}$ frequency and $0.1 \mu \mathrm{N} \cdot \mathrm{m}$ initial torque. The first time sweep was ended at the gelation 
point of each sample, which was the time of the crossover between $\mathrm{G}^{\prime}$ (storage modulus) and $\mathrm{G}^{\prime \prime}$ (loss modulus). A second time sweep was performed immediately after the first one to follow gel development. This sweep always had a duration of $45 \mathrm{~min}$ and was performed using the same initial parameters. Subsequently, a frequency sweep was run from 10 to $0.01 \mathrm{~Hz}$ at a controlled stress of $0.5 \mathrm{~Pa}$. At last, a strain sweep was performed (at $1 \mathrm{~Hz}$ ) to ensure that the parameters applied during the previous tests were within the linear viscoelastic region of the sample.

\subsection{Rennet activity}

The release of the casein macropeptide (CMP) from $\kappa$-casein by enzyme action was measured with RP-HPLC. After addition of rennet, each sample was divided in aliquots in different test tubes. Every $5 \mathrm{~min}$, trichloroacetic acid (TCA) at a concentration of $40 \mathrm{~g} \cdot \mathrm{L}^{-1}$ (final concentration in the sample of $20 \mathrm{~g} \cdot \mathrm{L}^{-1}$ ) was added in the tubes to stop the enzymatic reaction. The experiment was performed at constant temperature of $30{ }^{\circ} \mathrm{C}$ for $45 \mathrm{~min}$. After TCA addition, each sample was mixed using a vortex mixer and stored overnight at $4{ }^{\circ} \mathrm{C}$. The next day, all samples were equilibrated at room temperature and centrifuged at $4500 \times g$ for $15 \mathrm{~min}$, with an Eppendorf 5415D centrifuge (Brinkmann Instruments Ltd., Mississauga, ON, Canada). The supernatants were separated with a syringe, filtered through $0.45 \mu \mathrm{m}$ MillexGV filters and analysed by chromatography.

RP-HPLC was carried out with a Finnigan SpectraSystem LC unit comprising a degasser, pump, autosampler with a $100 \mu \mathrm{L}$ sample loop and UV detector (at $210 \mathrm{~nm}$ ). The sample was loaded into a Vydac C4 guard column (Mandel, USA), then into the column, a Pharmacia Biotech $\mu R P C \quad C 2 / C 18$ ST 4.6/100 (Piscataway, $\mathrm{NJ})$. Using a flow rate of $1 \mathrm{~mL} \cdot \mathrm{min}^{-1}$, a nonlinear gradient was run between solvent $\mathrm{A}\left(1 \mathrm{~mL} \cdot \mathrm{L}^{-1} \mathrm{TFA}\right.$ in water $)$ and solvent $\mathrm{B}\left(1 \mathrm{~mL} \cdot \mathrm{L}^{-1} \mathrm{TFA}\right.$ in $900 \mathrm{~mL} \cdot \mathrm{L}^{-1}$ acetonitrile). The elution started at $18 \%$ solvent $\mathrm{B}$, increasing to $39 \%$ in $35 \mathrm{~min}$ and to $100 \%$ in the next $6 \mathrm{~min} ; 100 \%$ solvent $\mathrm{B}$ was then kept constant for $8 \mathrm{~min}$ before decreasing back to $18 \%$ in the last 4 min of run. For each sample, the peak area was integrated using ChromQuest (version 4.1, ThermoFinnigan, Burlington, ON, Canada).

\subsection{Statistical analysis}

All the experiments were carried out in triplicate and mean values are reported unless otherwise indicated. All the figures presented in this work contain graphs that are the most representative of the three replicates. Analysis of variance and least significant difference computations were carried out in order to determine eventual significant differences between treatments. Statistical analyses were conducted using SPlus 8.0 and differences were considered at $95 \%$ confidence level.

\section{RESULTS}

\subsection{Characterization of homogenized milk systems}

TEM, SDS-PAGE and light scattering techniques were used to characterize the different milk samples: homogenized milk (HM), homogenized milk with Tween 20 (HM-Tw) and skim milk (SM); the latter used as a reference to the behaviour of caseins in isolation.

Transmission electron micrographs of the homogenized milk are shown in Figure 1. Homogenization of whole milk reduces the size of the fat globules and creates a heterogeneous fat globule distribution. Two main populations of fat globules can be identified; the largest globules, of $300-400 \mathrm{~nm}$ in diameter, are covered with the milk fat globule membrane and partially 

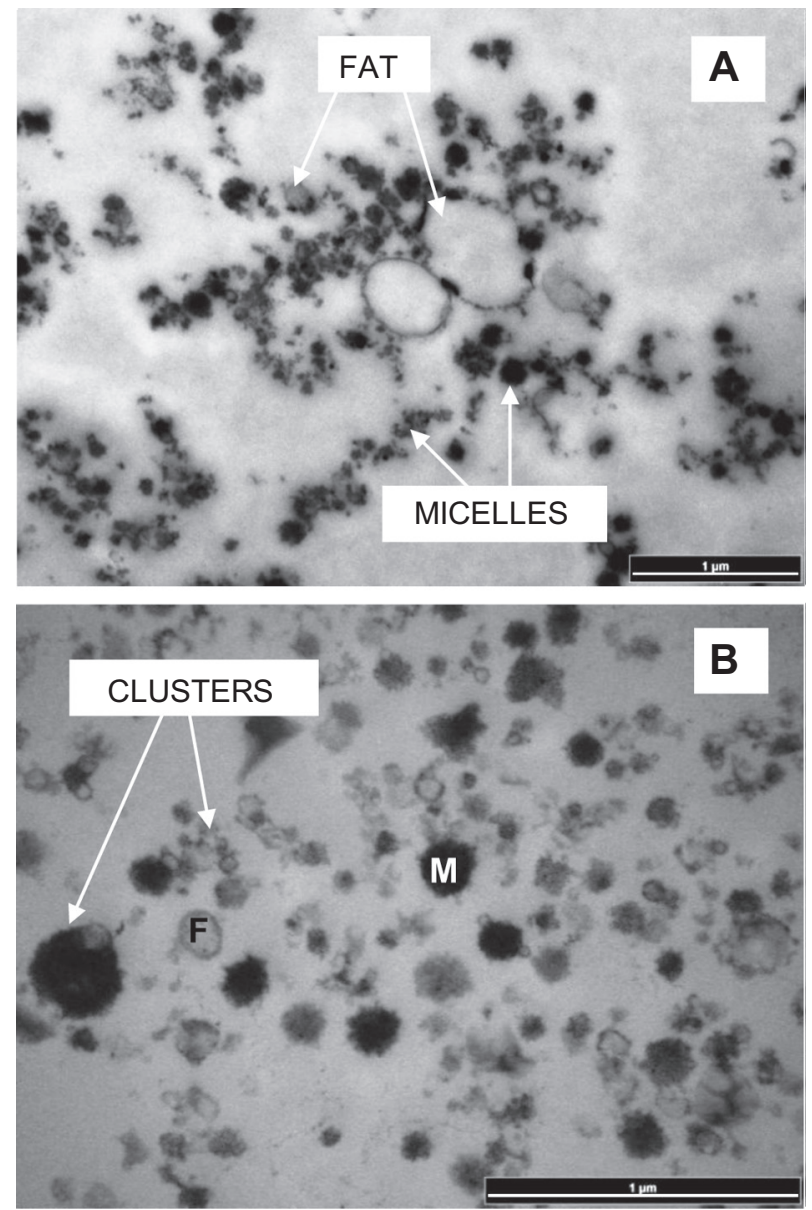

Figure 1. Transmission electron micrographs of homogenized milk. (A) Magnification of 46000 (scale bar $=1 \mu \mathrm{m}$ ); (B) magnification of 25000 (scale bar $=1 \mu \mathrm{m}$ ), showing fat globules $(\mathrm{F})$ and casein micelles (M, heavily stained). Clusters of casein micelles and small globules are also indicated in the images.

spread casein micelles (Fig. 1A). The second population has very small globules, with diameters $<100 \mathrm{~nm}$, which in some cases appear to be clustered with the micelles either by direct interaction or by incorporation into them (Fig. 1B). These observations confirm those of previous reports [4].

The proteins in the serum and cream phases of the homogenized milk samples were analysed with SDS-PAGE (Fig. 2) to confirm that Tween 20 caused protein displacement from the interface. While in homogenized milk there is a clear presence of casein proteins in the cream phase (Lane 3 ), very little protein is left in the cream phase of the same sample after incubation with Tween 20 (Lane 4). The addition of Tween 20 to homogenized milk leads to the interfacial replacement 


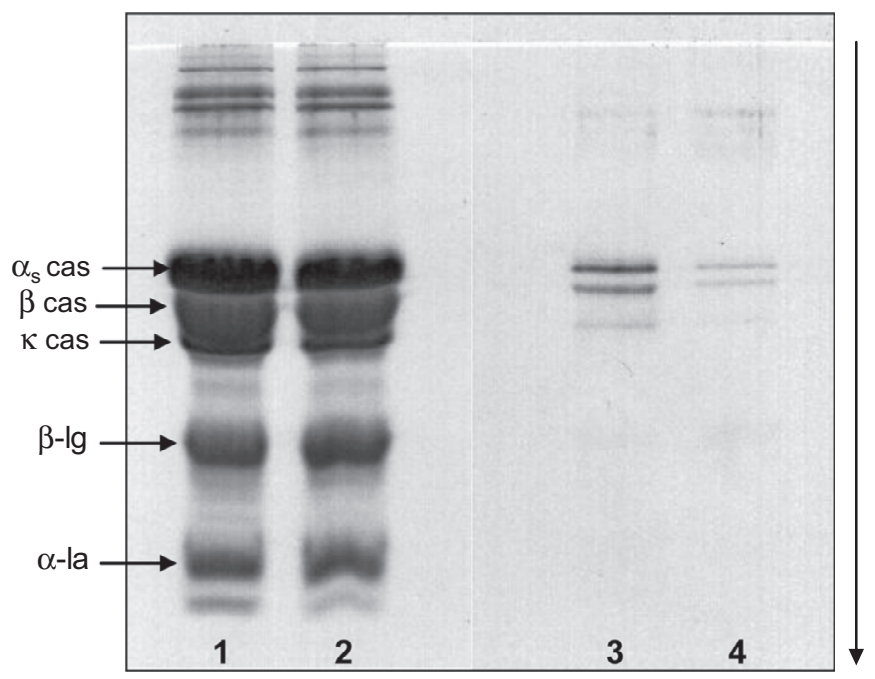

Figure 2. SDS-PAGE conducted under reducing conditions of homogenized milk with or without 2\% Tween 20. Lane 1: homogenized milk serum; Lane 2: serum of homogenized milk with Tween; Lane 3: homogenized milk cream; and Lane 4: cream of homogenized milk with Tween. The arrow represents the direction of migration (cas $=$ casein, $\beta$-lg $=\beta$-lactoglobulin and $\alpha$-la $=$ $\alpha$-lactalbumin).

of the proteins by the surfactant and results in the removal of casein micelles from the surface of the globules into solution.

Figure 3 summarizes the results on size distribution analysis of SM, HM and HM-Tw, carried out using integrated light scattering. Skim milk shows a monomodal distribution of sizes with an average diameter around $120 \mathrm{~nm}$. This is expected, as only casein micelles are present in skim milk. Both the HM and HM-Tw samples show a bimodal distribution of sizes, with fat globules sizes of about $1.2 \mu \mathrm{m}$ of diameter. While integrated light scattering does not show significant differences in the size of the fat globules in homogenized milk with or without Tween, there is a significant reduction in the average apparent diameter of the particles (from $271 \pm 7.1$ to $216 \pm 7.3 \mathrm{~nm}$ ) in the presence of Tween, when the size is measured by DLS. The smaller average size measured by DLS can be attributed to the displacement of the casein micelles from the interface as well as the disruption of clusters.

\subsection{Renneting}

The first phase of the enzymatic coagulation by rennet can be monitored by measuring the release of CMP from the surface of casein micelles. Figure 4 shows the percentage of CMP released over time after addition of rennet. The maximum CMP released (maximum area) in skim milk control was taken as $100 \%$ release, and all measurements were compared to this value. All the samples reached the maximum value ofCMP released (100\%). HM and HM-Tw show a statistically significant difference in the release of CMP compared to control SM, showing a slower CMP release compared to the HM and HM-Tw. Table I indicates the difference in the time necessary to reach $95 \%$ CMP release. On the other hand, no differences were measured between homogenized milk 


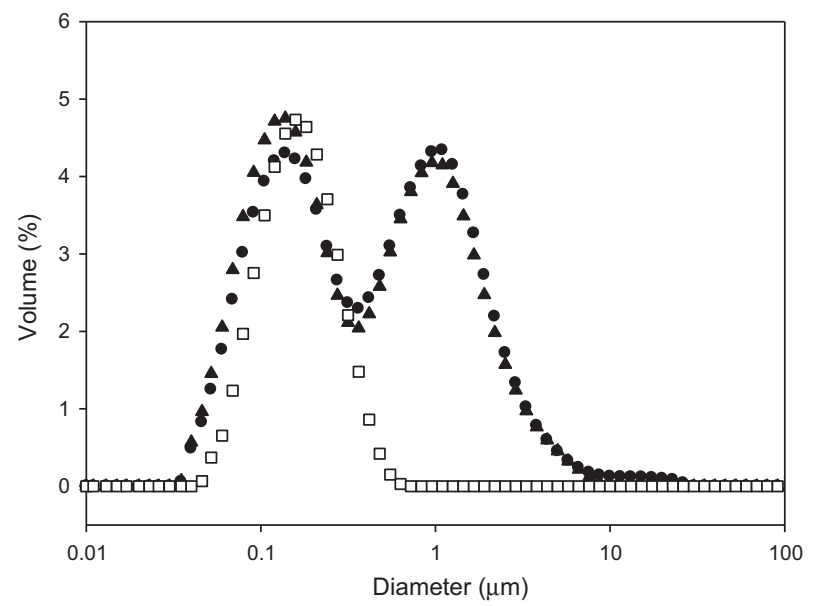

Figure 3. Particle size distribution obtained by integrated light scattering of skim milk (口), homogenized milk $(\bullet)$ and homogenized milk with Tween $(\boldsymbol{\Delta})$.

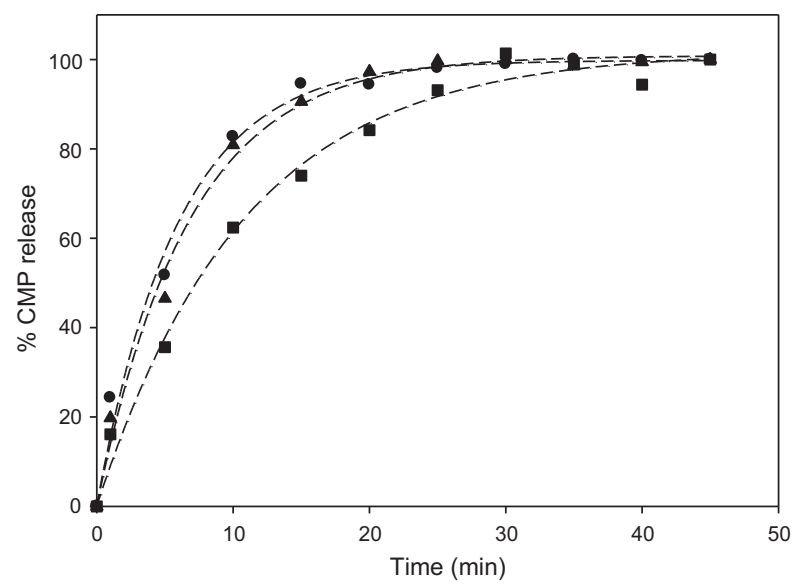

Figure 4. \% CMP release versus time after addition of rennet for skim milk (๘), homogenized milk $(\bullet)$ and homogenized milk with Tween $(\boldsymbol{\Lambda})$.

with or without Tween. These results were also confirmed by using half of the rennet concentration (not shown).

To follow the kinetics of aggregation of the caseins and fat globules during gelation, DWS and rheology experiments were performed. Figure $5 \mathrm{~A}$ shows the behaviour of the storage modulus, $\mathrm{G}^{\prime}$, measured by rheology, as a function of renneting time. The gelation point of milk is clearly accelerated by the presence of fat globules, as skim milk shows the slowest gelation point compared to homogenized milk. In addition, HM-Tw gelled significantly earlier than HM (see Tab. I for statistical differences). The elastic modulus of the gel was also 
Table I. Rennet-coagulation parameters obtained for skim milk (SM), homogenized milk (HM) and homogenized milk with Tween (HM-Tw). The values are the means of three replicates. Means in the same column with no common superscript are statistically different $(P<0.05)$.

\begin{tabular}{lcccccc}
\hline & $\begin{array}{c}95 \% \text { CMP } \\
(\min )\end{array}$ & $\begin{array}{c}\text { Gel point } \\
(\min )\end{array}$ & $\begin{array}{c}1 / /^{*} \\
(\mathrm{~min})\end{array}$ & $\begin{array}{c}\text { Radius } \\
(\min )\end{array}$ & $\mathrm{G}^{\prime}$ after 45'(Pa) & $\begin{array}{c}\text { \% Strain at } \\
\text { break }\end{array}$ \\
\hline $\mathrm{SM}$ & $28.9^{\mathrm{a}}$ & $37.5^{\mathrm{a}}$ & $16.5^{\mathrm{a}}$ & $36.3^{\mathrm{a}}$ & $43.2^{\mathrm{a}}$ & $20.22^{\mathrm{a}}$ \\
$\mathrm{HM}$ & $17.2^{\mathrm{b}}$ & $25.6^{\mathrm{b}}$ & $9.4^{\mathrm{b}}$ & $16.6^{\mathrm{b}}$ & $52.7^{\mathrm{a}}$ & $33.66^{\mathrm{a}}$ \\
$\mathrm{HM}-\mathrm{Tw}$ & $15.6^{\mathrm{b}}$ & $14.7^{\mathrm{c}}$ & $7.3^{\mathrm{c}}$ & $10.3^{\mathrm{c}}$ & $106.2^{\mathrm{b}}$ & $33.37^{\mathrm{a}}$ \\
\hline
\end{tabular}

modified by the presence of fat; in fact the rate of growth of $\mathrm{G}^{\prime}$ is faster for HM than skim milk and even faster for HM-Tw.

Figure 5B shows the development of $1 / l^{*}$ as a function of time after addition of rennet. The parameter is normalized as homogenized milk does not only contain casein micelles but also fat globules, and therefore contains two scatterers with different scattering properties. This results in absolute values of $1 / l^{*}$ quite different compared to those of skim milk control. Since we are interested in the kinetics of gel formation with time, and not necessarily in the absolute values of turbidity, normalization can be justified. The presence of the fat globules in homogenized milk samples heavily skews the light signal $[7,8]$. Their larger size as well as their higher refractive index contrast compared to the caseins dominates the scattering of light and the results shown by DWS for homogenized milk reflect the behaviour of the fat globules as affected by the formation of a casein gel around them $[7,8]$.

All the samples show a delay phase before manifesting a change in $1 / l^{*}$. After this delay, $1 / l^{*}$ starts to increase, reflecting the beginning of interparticle interactions due to the action of rennet. The overall behaviour of $1 / l^{*}$ of all the samples is related to the development and later formation of a gel [25]. It appears that $1 / l^{*}$ increases earlier in homogenized milk samples than in skim milk, and HM-Tw shows a change before HM. These differences are statistically significant (see Tab. I). After the initial $1 / l^{*}$ increase, there is a second change in slope which corresponds directly to the beginning of the aggregation of casein micelles (see Fig. 5C); this is more evident for SM and HM-Tw samples than for HM. In skim milk samples, the increase of $1 / l^{*}$ is continuous and does not seem to reach a limit within the experimental time. On the contrary, homogenized milk and HM-Tw show a plateau, with some delay for HM with Tween, and almost immediate for HM.

The particle's aggregation can be followed also by measuring the apparent radius of the scatterers over time (Fig. 5C). Although an increase in apparent radius after gelation has no physical meaning, this change reflects the decrease in diffusion (or mobility) of the scattering particles. Confirming what was already observed by rheology (Fig. 5A) and with the $1 / l^{*}$ parameter measurements (Fig. 5B) also in the case of the radius as a function of time, it is clear that the coagulation time is accelerated by the presence of fat globules (HM and HM-Tw aggregate earlier than $\mathrm{SM}$ ). In addition, there is a significantly faster aggregation in the sample containing Tween. The size change (or more correctly, the rate of decrease of diffusion) is quite fast in SM and HM samples, suggesting in the latter the interaction of the fat globules with the casein network. On the other hand, in HM-Tw, although the coagulation time is significantly faster than for $\mathrm{HM}$ and $\mathrm{SM}$ 


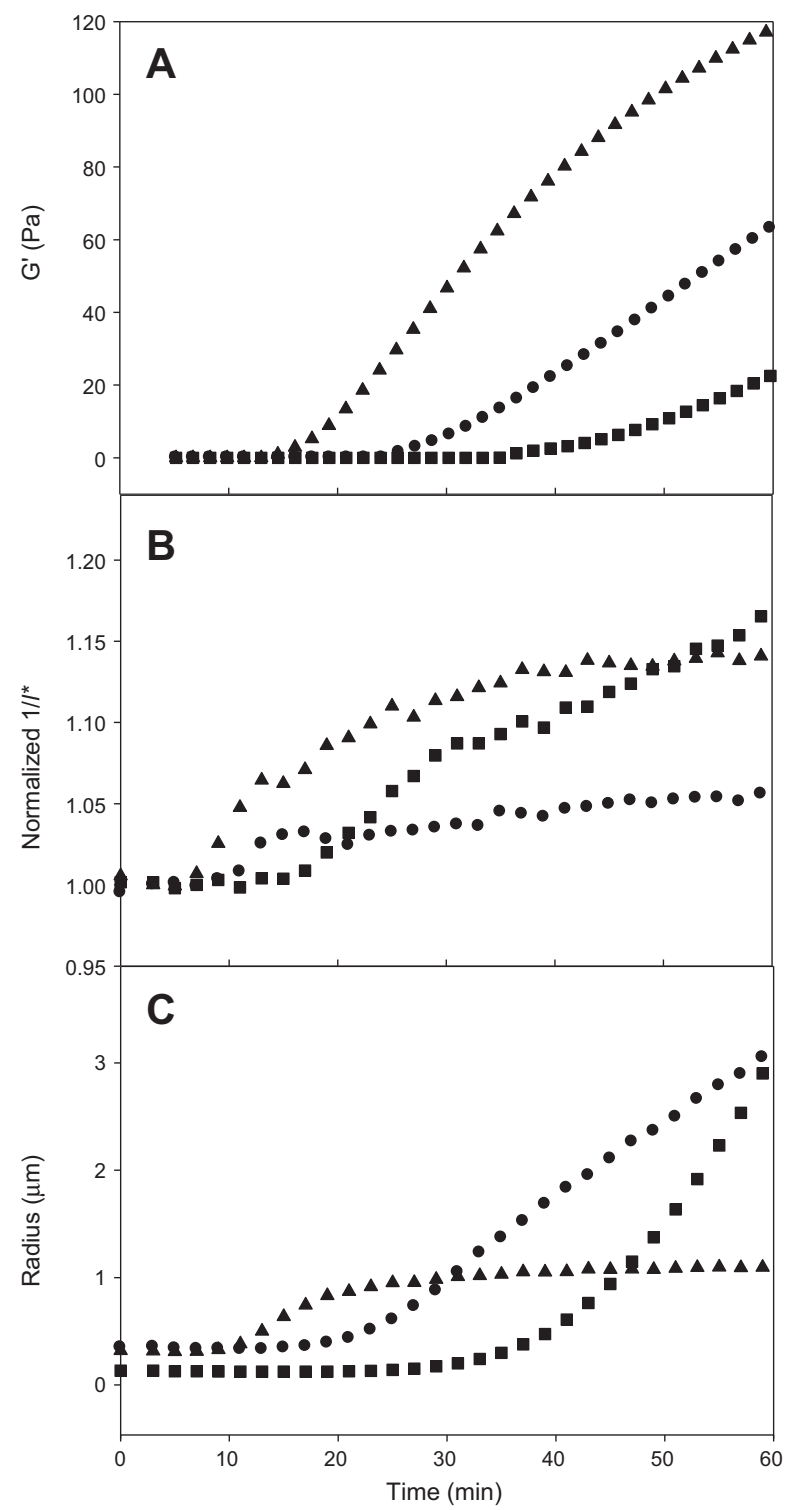

Figure 5. Rennet-coagulation process monitored using rheological and DWS parameters: $\mathrm{G}^{\prime}(\mathrm{A})$, $1 / /^{*}(\mathrm{~B})$ and radius (C) as a function of time after addition of rennet. Skim milk ( $\left.\mathbf{(}\right)$; homogenized milk $(\bullet)$; homogenized milk with Tween $(\boldsymbol{\Delta})$.

samples, the apparent radius does not increase continuously, but rather reaches a plateau at about $1 \mu \mathrm{m}$.
Figure 6 shows the difference in the development of the MSD for SM and HM with or without Tween. Each line 


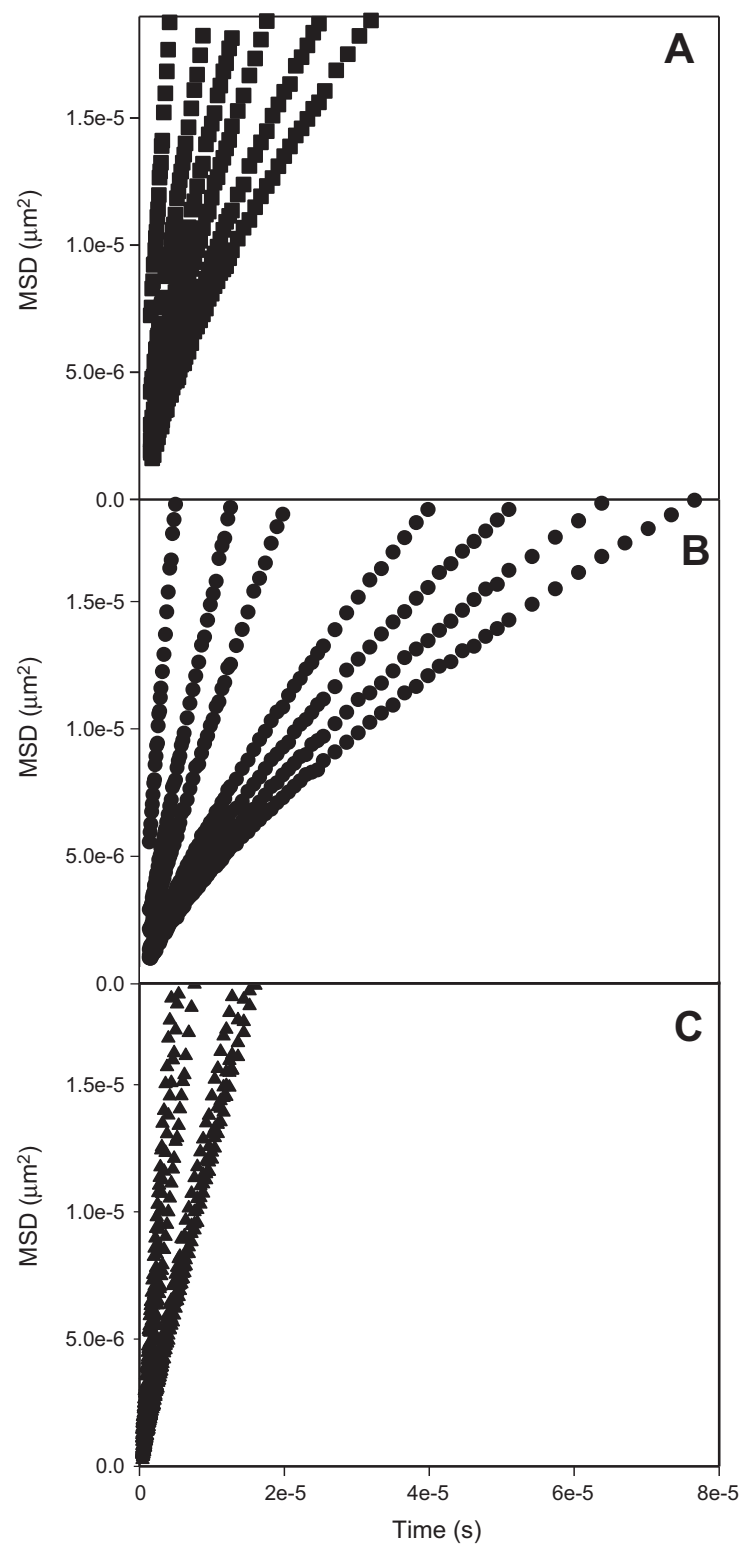

Figure 6. MSD as a function of time for skim milk (A), homogenized milk (B) and homogenized milk with Tween (C). Process develops from left to right.

corresponds to a different time during the gelation process (with the reaction times increasing from left to right). A linear dependence of the MSD with correlation time indicates free diffusive motion [16]. During the initial stages after rennet 


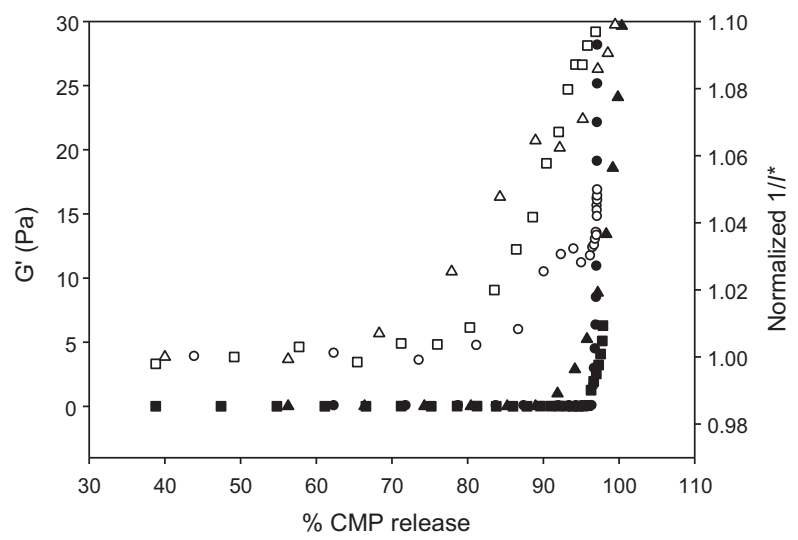

Figure 7. Development of $\mathrm{G}^{\prime}$ (full symbols) and $1 / l^{*}$ (open symbols) as a function of the amount of CMP released: skim milk $(\square, \varpi)$; homogenized milk $(\odot, \bullet)$ and homogenized milk with Tween $(\triangle, \mathbf{\Lambda})$.

addition, all samples show a linear dependence of the MSD, as the scatterers are free diffusing. Before the enzyme has a chance to cleave enough $\kappa$-casein off the surface of the micelles, both fat globules and micelles are free to probe the full accessible space range, resulting in a linear increase of MSD with time. As the micelles initially develop into small clusters, the diffusion of these aggregates slows down (compared to the initially free casein micelles and fat globules) and this results in a decrease of the slope of the linear graph. This is also evidenced in Figure 6, in the lines corresponding to the intermediate time after rennet addition. However, differences in the MSD slopes can be seen between the samples. At the gelation point, the time dependence of MSD evolves from linear to asymptotic for SM and HM. Homogenized milk shows a drastic decrease in the slope of the MSD curve when compared to SM. When Tween is present in the homogenized milk, there is a very little change in the MSD slope over time.

To better understand if the differences observed in the rheological and light scattering parameters are related to the amount of
CMP released during the renneting reaction, the change of $1 / l^{*}$ and $\mathrm{G}^{\prime}$ are plotted as a function of CMP release in Figure 7. In the case of SM, $1 / l^{*}$ starts to increase after around $80 \%$ of CMP has been released; however, the $\mathrm{G}^{\prime}$ value increases at about 95\% of CMP release. Homogenized milk has a similar behaviour to skim milk. On the other hand, in HM-Tw, $1 / l^{*}$ and $\mathrm{G}^{\prime}$ increase at lower levels of CMP released ( $75 \%$ and $90 \%$, respectively) than the other two samples.

All rheology and DWS experiments were also carried out with half the amount of rennet (results not shown). Although the kinetics of coagulation were obviously slower due to the decreased amount of rennet, the exact same behaviours were observed for the SM, HM and HM-Tw systems, demonstrating that the effects shown in this work are not dependent on the kinetics of aggregation of casein micelles but are rather related to interaction effects.

Table I summarizes the differences in the key parameters described above with the corresponding statistical significance. The presence of casein-covered fat globules significantly reduces the beginning 
of interparticle interaction (initial increase in $\left.1 / l^{*}\right)$ as well as the coagulation point measured by DWS and rheology. When the interface is replaced by Tween, the reduction is amplified. Table I also shows $\mathrm{G}^{\prime}$ values of the milk gels $45 \mathrm{~min}$ after the gelation point. Statistically, there seems to be no difference in the value of $\mathrm{G}^{\prime} 45 \mathrm{~min}$ after the gelation point between the SM and HM (Tab. I). When Tween replaces the milk proteins at the interface, the final $\mathrm{G}^{\prime}$ value more than doubles compared to that of SM.

The $\%$ strain at break of the gels obtained from all the samples was calculated as a change of $5 \%$ in $\mathrm{G}^{\prime}$ during the strain sweeps (Tab. I). The presence of fat globules does not alter the brittleness of milk gels, the gels show a break at about $30 \%$ strain. However, the presence of Tween in HM induces a biphasic behaviour in the strain sweep; when an increased strain is applied to these gels, there is an initial change in $\mathrm{G}^{\prime}$ (about 2\%) at around 3.5\% strain, meaning that the structure is somehow modified, but the linear viscoelastic range still extends to $30 \%$ strain, as in SM and HM. Again, these tests were also performed on gels prepared with a lower amount of rennet, and the nature of the results was fully conserved.

\section{DISCUSSION}

Homogenization reduces the size of the fat globules, creating a heterogeneous fat globules distribution with casein-coated globules either free in the serum or clustered with casein micelles. Similar results were obtained homogenizing whole milk with a Microfluidizer [4].

It is established that when small molecular weight surfactants are added to a protein-stabilized emulsion, they migrate to the fat/water interface and displace the stabilizing proteins [15]. In this work, using Tween 20 , it was possible to create a colloi- dal system with a similar distribution of fat globule sizes as in homogenized milk but with a different interface, as Tween 20 displaces most of the proteins present at the interface (Figs. 2 and 3).

The primary phase of renneting was faster in HM and HM-Tw than in SM, and in all samples, all of the $\kappa$-casein was still available for hydrolysis (Fig. 4). The homogenization process forces casein micelles to adsorb and spread at the oil/ water interface. It has been previously hypothesized that spreading of casein micelles at the interface increases the susceptibility of $\kappa$-casein to enzymatic hydrolysis by rennet [21]. The similar kinetics between HM and HM-Tw samples suggest that even after displacement of the micelles from the interface by the surfactant, the susceptibility to hydrolysis does not change.

It is important to note that it has previously been shown that addition of Tween 20 to skim milk increases the rate of CMP release [12]. Although the molecular mechanism origin of this effect is not yet clear, it has been hypothesized that Tween molecules modify the supramolecular organization of the casein micelles, most likely on the surface. The results shown in this work suggest that once the supramolecular structure of the casein micelles has been modified by surface adsorption, the addition of Tween 20 no longer affects the primary phase of renneting.

Both rheology and light scattering measurements showed a decrease of the gelation point of homogenized milk compared to skim milk. This can be attributed to the faster removal of $\kappa$-casein in the first stages of the enzymatic reaction and is in full agreement with the results obtained by measuring the CMP release (Figs. 4 and 7). As the micelles are stripped of their stabilizing layer, they are able to come into close contact and aggregate earlier.

The addition of Tween 20 to homogenized milk significantly accelerates the secondary stage of gelation. There was also 
a significant difference in the elastic modulus for the gels prepared from homogenized milk with and without Tween 20. This was previously observed for skim milk samples (with no oil droplets) in the presence of Tween 20 [12]. These results are in contrast with the understanding that Tween-covered oil droplets would act as "inert" fillers in the renneted casein network $[2,9]$. The oil droplets in the HM-Tw samples are relatively inert, as shown by the behaviour of the MSD (Fig. 6, see below), and the differences between HM-Tw and HM can be attributed to a number of factors. First of all, the presence of Tween 20 affects both the primary and secondary stages of the aggregation in skim milk samples [12]; in addition, the HM-Tw, because of the protein displacement, has a higher amount of protein present in solution compared to HM milk, and finally, the displaced casein micelles may be more susceptible to aggregation because of surface denaturation.

The overall behaviour of $1 / l^{*}$ (Fig. 5B) for $\mathrm{SM}$ and all the homogenized milk samples was in full agreement with that reported in previous studies on the rennet coagulation of casein micelles in skim milk [25]. The onset of change of $1 / l^{*}$ is much earlier for HM-Tw than for homogenized and skim milk, confirming what is shown in Figure 5A (rheology results). Considering the inert role of the fat globules (mostly covered with Tween), it may be hypothesized that the casein micelles are more prone to aggregation either because of a direct effect of Tween 20 on the structure of the casein micelles, or because of the presence of more protein in solution or, more likely, because of the displaced surface-denatured casein micelles.

The differences noticed in the development of the turbidity parameter, $1 / l^{*}$, in the two homogenized milk systems reflect the different colloidal state of the filler particles (Fig. 5B). In HM, the fat globules are an active part of the network, however, because of the increased volume fraction, the overall spatial distribution reaches its final state (plateau value) much sooner than in SM. On the other hand, when Tween 20 is added to HM, the fat globules shall not interact with the caseins and contribute to the formation of a gel, and they will simply reside in the pockets created by the gel network. Only once the casein gel formed and the fat globules are "in place", their average positions will not change with time. This forcing of the droplets into pockets also explains the much larger change in the relative value of $1 / l^{*}$ : the spatial distribution of the oil droplets after the formation of a gel is more different from the liquid state than the spatial distribution of the oil droplets in HM gels.

By monitoring with DWS the increase in radius (or decrease in diffusion) over time it can be noticed that skim milk and HM had a similar gel-driving process, as the rate of "decrease of diffusion" was high and relatively similar (Fig. 5C). This is in agreement with the current understanding that homogenized milk fat globules are fully incorporated in the casein network, and as such, slow down as the network formation progresses. On the other hand, in HM-Tw, the apparent radius reaches a plateau quite quickly, revealing the presence of a system in dynamic steady-state. This is in full agreement with the results shown in Figure $5 \mathrm{~B}$ and can be interpreted by the enclosure of the fat droplets, un-aggregated, inside the gel protein network. This has been previously shown also for renneting of recombined milk $[7,8]$.

The particle dynamics can be also monitored with the MSD parameter as a function of time. At the gelation point, the scattering particles in SM and HM become trapped in a network; their arrest in motion is shown in the deviation from linearity of the MSD curves (Fig. 6). However, as the Tween-covered fat globules do not interact with the network, HM-Tw samples do not show this transition. The MSD dependence with time remained linear throughout the duration of the experiment, in spite of 
the formation of a gel (as shown by the increase of the elastic modulus, $\mathrm{G}^{\prime}$, shown in Fig. 3). This behaviour is consistent with the notion that Tween-covered fat globules do not take active part in the formation of the casein gel. The fat globules are trapped in the network cages, but within the length scale probed $(<10 \mathrm{~nm}$, see Fig. 6) they take unimpeded excursions (they are not an integral part of the gel strand).

It is therefore possible to conclude that homogenized milk showed a coagulation behaviour similar to that of skim milk; the presence of casein micelles at the fat interface did not modify the secondary phase of renneting. In fact, the micelles in homogenized milk aggregate earlier than in SM as a direct consequence of the acceleration of the first phase of renneting (see Figs. 5 and 7). On the other hand, in HM-Tw less CMP has to be removed to destabilize the system. This lower level of proteolysis required for coagulation leads to a faster aggregation of HM-Tw casein micelles compared to HM. The earlier aggregation can be attributed to an effect of Tween 20 on the casein micelles and not to an effect of non-interacting fat globules. It has been previously shown [12] that the addition of Tween to skim milk not only affects the primary stages of renneting but also accelerates the second phase of the coagulation process, reducing the amount of CMP that needs to be released to destabilize the system towards aggregation. In the HM-Tw, it is also important to consider that there was an increased presence of surface-denatured casein micelles in solution during renneting.

The increase in $\mathrm{G}^{\prime}$ of HM-Tw gels cannot be related only to the increase in volume fraction of the system, as HM has the same colloidal content as HM-Tw, and the Tween-stabilized oil droplets are not showing significant aggregation (see Fig. 6) nor interactions with the caseins. Previous work showed a significant increase in the stiffness of the gels in the presence of Tween when no fat globules are present [12], therefore it is possible to conclude that the increase in stiffness does not depend on the Tweenstabilized fat globules - but from the effect of Tween molecules on the structure of the casein micelles.

This analysis of the physico-chemical properties of the gels and their structuring properties suggests that, by fine-tuning the interactions occurring during the formation of the renneted casein network, it may be possible to design gels with different textural and sensorial properties.

Acknowledgements: This work was partly funded by the Ontario Dairy Council and the Natural Sciences and Engineering Council of Canada. In addition, funding by Kraft Foods $\mathrm{R} \& \mathrm{D}$ (Chicago, IL) is gratefully acknowledged.

\section{REFERENCES}

[1] Cano-Ruiz M.E., Richter R.L., Effect of homogenization pressure on the milk fat globule membrane proteins, J. Dairy Sci. 80 (1997) 2732-2739.

[2] Cho Y.H., Lucey J.A., Singh H., Rheological properties of acid milk gels as affected by the nature of the fat globule material and heat treatment of milk, Int. Dairy J. 9 (1999) 537-545

[3] Dalgleish D.G., Alexander M., Corredig M., Studies of the acid gelation of milk using ultrasonic spectroscopy and diffusing wave spectroscopy, Food Hydrocoll. 18 (2004) 747-755.

[4] Dalgleish D.G., Tosh S.M., West S., Beyond homogenization: the formation of very small emulsion droplets during the processing of milk by a Microfluidizer, Neth. Milk Dairy J. 50 (1996) 135-148.

[5] de Kruif C.G., Casein micelles interactions, Int. Dairy J. 9 (1999) 183-188.

[6] Everett D.W., Olson N.F., Dynamic rheology of renneted milk gels containing fat globules stabilized with different surfactants, J. Dairy Sci. 83 (2000) 1203-1209.

[7] Gaygadzhiev Z., Alexander M., Corredig M., Sodium caseinate stabilized fat globules inhibition of the rennet-induced gelation 
of casein micelles studied by diffusing wave spectroscopy, Food Hydrocoll. 23 (2009) 1134-1138.

[8] Gaygadzhiev Z., Corredig M., Alexander M., The impact of the concentration of casein micelles and whey protein-stabilized fat globules on the rennet-induced gelation of milk, Colloid Surf. B 68 (2009) 154-162.

[9] Gaygadzhiev Z., Hill A., Corredig M., Influence of emulsion droplet type on the rheological characteristics and microstructure of rennet gels from reconstituted milk, J. Dairy Res. 76 (2009) 1-7.

[10] Guinee T.P., Gorry C.B., O’Callaghan D.J., O'Kennedy B.T., O'Brien N., Fenelon M.A., The effects of composition on the rennet coagulation properties of milk, Int. J. Dairy Technol. 50 (1997) 99-106.

[11] Horne D.S., Steric stabilization and casein micelle stability, J. Colloid Interface Sci. 111 (1986) 250-260.

[12] Ion Titapiccolo G., Corredig M., Alexander M., Modification to the renneting functionality of casein micelles caused by non-ionic surfactants, J. Dairy Sci. 93 (2010) 506-514.

[13] Jana A.H., Upadhyay K.G., A comparative study of the quality of Mozzarella cheese obtained from unhomogenized and homogenized buffalo milks, Cult. Dairy Prod. J. 28 (1993) 16-22.

[14] Lopez C., Dufour E., The composition of the milk fat globule surface alters the structural characteristics of the coagulum, J. Colloid Interface Sci. 233 (2001) 241-249.

[15] Mackie A.R., Gunning A.P., Wilde P.J., Morris V.J., Orogenic displacement of proteins from the air/water interface by competitive adsorption, J. Colloid Interface Sci. 210 (1999) 157-166.

[16] Maret G., Wolf P.E., Multiple light scattering from disordered media. The effect of Brownian motion of scatterers, Z. Phys. B - Condensed Matter 65 (1987) 409-413.

[17] McMahon D.J., Brown R.J., Enzymatic coagulation of casein micelles: a review, J. Dairy Sci. 67 (1984) 919-929.

[18] Michalski M.C., Cariou R., Michel F., Garnier C., Native vs. damaged milk fat globules: membrane properties affect the viscoelasticity of milk gels, J. Dairy Sci. 85 (2002) 2451-2461.

[19] Mulder H., Walstra P., The milk fat globuleemulsion science as applied to milk products and comparable foods, Commonwealth
Agricultural Bureaux, Farnham Royal, Bucks, UK, 1974.

[20] Peters I.I., Cheddar cheese made from pasteurized milk homogenized at various pressure, J. Dairy Sci. 39 (1956) 1083-1088.

[21] Robson E.W., Dalgleish D.G., Coagulation of homogenized milk particles by rennet, J. Dairy Sci. 80 (1984) 1901-1907.

[22] Romer S., Sheffold S., Shurtenberger P., Sol-gel transition of concentrated colloidal suspensions, Phys. Rev. Lett. 85 (2000) 4980-4983.

[23] Rosa P., Sala G., van Vliet T., Van De Velde F., Cold gelation of whey protein emulsions, J. Text. Stud. 37 (2006) 516-537.

[24] Sandra S., Alexander M., Dalgleish D.G., The rennet coagulation mechanism of skim milk observed by diffusing wave spectroscopy, J. Colloid Interface Sci. 308 (2007) 364-373.

[25] Sandra S., Dalgleish D.G., The effect of ultra high-pressure homogenization (UHPH) on rennet coagulation properties of unheated and heated fresh skim milk, Int. Dairy J. 17 (2007) 1043-1052.

[26] Sharma R., Dalgleish D.G., Interactions between milk serum proteins and synthetic fat globule membrane during heating of homogenized whole milk, J. Agric. Food Chem. 41 (1993) 1407-1412.

[27] ten Grotenhuis E., Paques M., van Aken G.A., The application of diffusing wave spectroscopy to monitor the phase behaviour of emulsion-polysaccharide systems, J. Colloid Interface Sci. 227 (2000) 495-504.

[28] Tunick M.H., Effects of homogenization and proteolysis on free oil in Mozzarella cheese, J. Dairy Sci. 77 (1994) 2487-2493.

[29] van Vliet T., Dentener-Kikkert A., Influence of the composition of the milk fat globule membrane on the rheological properties of acid milk gels, Neth. Milk Dairy J. 36 (1982) 261-265.

[30] Walstra P., Bloomfield V.A., Jason Wei G., Jenness R., Effect of chymosin action on the hydrodynamic diameter of casein micelles, Biochim. Biophys. Acta 669 (1981) 258-259.

[31] Weitz D.A., Zhu J.X., Durian D.J., Gang H., Pine D.J., Diffusing-wave spectroscopy: The technique and some applications, Phys. Scr. T49B (1993) 610-621.

[32] Zoon P., van Vliet T., Walstra P., Rheological properties of rennet-induced skim milk gels. 3. The effect of calcium and phosphate, Neth. Milk Dairy J. 42 (1988) 295-312. 